\title{
Current Trends of Lung Cancer Surgery and Demographic and Social Factors Related to Changes in the Trends of Lung Cancer Surgery: An Analysis of the National Database from 2010 to 2014
}

\author{
Samina Park, MD \\ In Kyu Park, MD, PhD \\ Eung Re Kim, MD \\ Yoohwa Hwang, MD \\ Hyun Joo Lee, MD, PhD \\ Chang Hyun Kang, MD, PhD \\ Young Tae Kim, MD, PhD
}

\begin{abstract}
Purpose
We investigated current trends in lung cancer surgery and identified demographic and social
\end{abstract} factors related to changes in these trends.

\section{Materials and Methods}

We estimated the incidence of lung cancer surgery using a procedure code-based approach provided by the Health Insurance Review and Assessment Service (http://opendata.hira. or.kr). The population data were obtained every year from 2010 to 2014 from the Korean Statistical Information Service (http://kosis.kr/). The annual percent change (APC) and statistical significance were calculated using the Joinpoint software.

Results

From January 2010 to December 2014, 25,687 patients underwent 25,921 lung cancer surgeries, which increased by $45.1 \%$ from 2010 to 2014 . The crude incidence rate of lung cancer surgery in each year increased significantly (APC, 9.5; $p<0.05$ ). The male-to-female ratio decreased from 2.1 to 1.6 (APC, $-6.3 ; p<0.05$ ). The incidence increased in the age group of $\geq 70$ years for both sexes (male: APC, 3.7; $p<0.05$; female: APC, 5.96; $p<0.05$ ). Furthermore, the proportion of female patients aged $\geq 65$ years increased (APC, 7.2; $p<0.05$ ), while that of male patients aged < 65 years decreased (APC, $-3.9 ; p<0.05$ ). The proportions of segmentectomies (APC, 17.8; $p<0.05$ ) and lobectomies (APC, 7.5; $p<0.05$ ) increased, while the proportion of pneumonectomies decreased (APC, -6.3; $p<0.05)$. Finally, the proportion of patients undergoing surgery in Seoul increased (APC, $1.1 ; p<0.05$ ), while the proportion in other areas decreased (APC, $-1.5 ; p<0.05$ ).

\section{Conclusion}

An increase in the use of lung cancer surgery in elderly patients and female patients, and a decrease in the proportion of patients requiring extensive pulmonary resection were identified. Furthermore, centralization of lung cancer surgery was noted.

\section{Key words}

Lung neoplasms, Thoracic surgery, Incidence, Republic of Korea

\section{Introduction}

Lung cancer is the leading cause of cancer death in the world and in Korea [1,2]. In 2012, 1.82 million cases (12.9\% of the total number of cancer cases) of lung cancer were diagnosed and it caused 1.6 million deaths worldwide. Interestingly, incidence rate among females in Eastern Asia is somewhat high, despite the low smoking rate [2,3]. In Korea, a total of 22,118 new cases of lung cancer were reported and the crude rate of lung cancer was 43.9 per 100,000 persons in 2012 [4]. It is estimated that there will be 25,640 new cases of lung cancer and a crude rate of 50.4 per 100,000 persons in 2015 [5]. In the United States, lung cancer survival has already improved and the incidence of localized lung cancer has increased [6,7]. Although surgical resection remains the treatment of choice for early-stage lung cancer, only $22 \%$ of new lung cancer cases are localized diseases in Korea $[4,8,9]$.

The survival benefit of low-dose chest computed tomog- 
raphy (LDCT) related to a stage shift was reported in 2011 [10]. Additionally, differences in lung cancer incidence, smoking prevalence, and life expectancy patterns between males and females have been reported $[1,11,12]$. These factors related to population composition and cancer prevention policies can affect the incidence of the disease and treatment modalities.

Korea has abundant health care resources and utilization in terms of the number of hospitals, hospital beds, computed tomography scanners, and consultations with doctors per population [3]. The Korean government has operated National Health Insurance Service (NHIS), which covers over $98 \%$ of the Korean population, for over 30 years [13]. Additionally, the Korean Health and Insurance Review and Assessment Service (HIRA) collects reimbursement records from all claims made under NHIS and nation-wide information related to a specific disease, and treatment is available without patient identifiers. However, few studies have investigated national trends in lung cancer surgery, and some that have are out of date [14-17]. Thus, we investigated current trends in lung cancer surgery and identified demographic and social factors related to changes in these trends utilizing the Korean NHIS database from 2010 to 2014.

\section{Materials and Methods}

\section{Data acquisition}

We estimated the incidence of lung cancer surgery using a procedure code-based approach provided by the HIRA (http:// opendata.hira.or.kr). We assessed the information for lung cancer surgery, which was converted to specific procedure codes. The following surgical procedures with their codes were investigated, mediastinal lymph node dissection in conjunction with pulmonary resection (O1597), pulmonary segmentectomy (O1410), single lobectomy (O1421), bilobectomy (O1422), lobectomy in conjunction with segmentectomy (O1423), sleeve lobectomy (O1424), pneumonectomy (O1431), and sleeve pneumonectomy (O1432). We considered $\mathrm{O} 1597$ to be the standard surgical procedure for lung cancer.

All Korean residents have a specific registered number. Population data were obtained on July 1 of every year from 2010 to 2014 from the Korean Statistical Information Service (http://kosis.kr/).

\section{Statistical analysis}

We summarized the results using crude rates (the number of lung cancer surgeries divided by the population in a specific year) of lung cancer surgery and age-specific rates of lung cancer surgery. Age-standardized rates were calculated using the information describing the Korean standard population in 2010. Numerical data from open data are presented with numbers and percentage. Annual percent changes (APC) in incidences, proportions, ratios, and their statistical significance were calculated using the Joinpoint software ver. 4.2.0.2 from the Surveillance Research Program of the United States National Cancer Institute.

\section{Results}

\section{Incidence rate of lung cancer surgery}

From January 2010 to December 2014, 25,687 patients underwent 25,921 lung cancer surgeries. In 2010, 4,150 patients underwent surgery, while in 2014, 6,021 patients underwent surgery, which is an increase of $45.1 \%$ (Table 1 ). The crude incidence rate of lung cancer surgery in each year increased significantly (APC, 9.5; $\mathrm{p}<0.05$ ).

\section{Incidence by sex}

In 2010, male patients accounted for $67.3 \%$ of all lung cancer patients; however, the proportion of female patients increased consistently over the subsequent years. The maleto-female ratio decreased from 2.1 in 2010 to 1.6 in 2014 (APC, $-6.3 ; \mathrm{p}<0.05$ ). Although the number of lung cancer surgeries increased in both male and female patients, the proportion according to age group changed depending on sex. The proportion of female patients aged $\geq 65$ years increased significantly over the study period (APC, 7.2; $<<0.05$ ), while the proportion of male patients aged $<65$ years decreased significantly (APC, $-3.9 ; \mathrm{p}<0.05)$ (Table 2$)$. The proportion of female patients aged $<65$ years tended to increase, while the proportion of male patients aged $\geq 65$ years tended to decrease over the study period, although these changes were not statistically significant.

\section{Incidence by age distribution}

The age distribution of lung cancer surgeries varied by sex and shifted (Fig. 1). The highest proportion over the study period was observed among individuals aged 60-69 years. The proportion increased in the age group of $\geq 70$ years for both sexes (male: APC, 3.7; p < 0.05; female: APC, 6.0; $<<$ $0.05)$. Female patients were more likely to be younger than male patients. In 2014, the age groups of 60-69 years and 


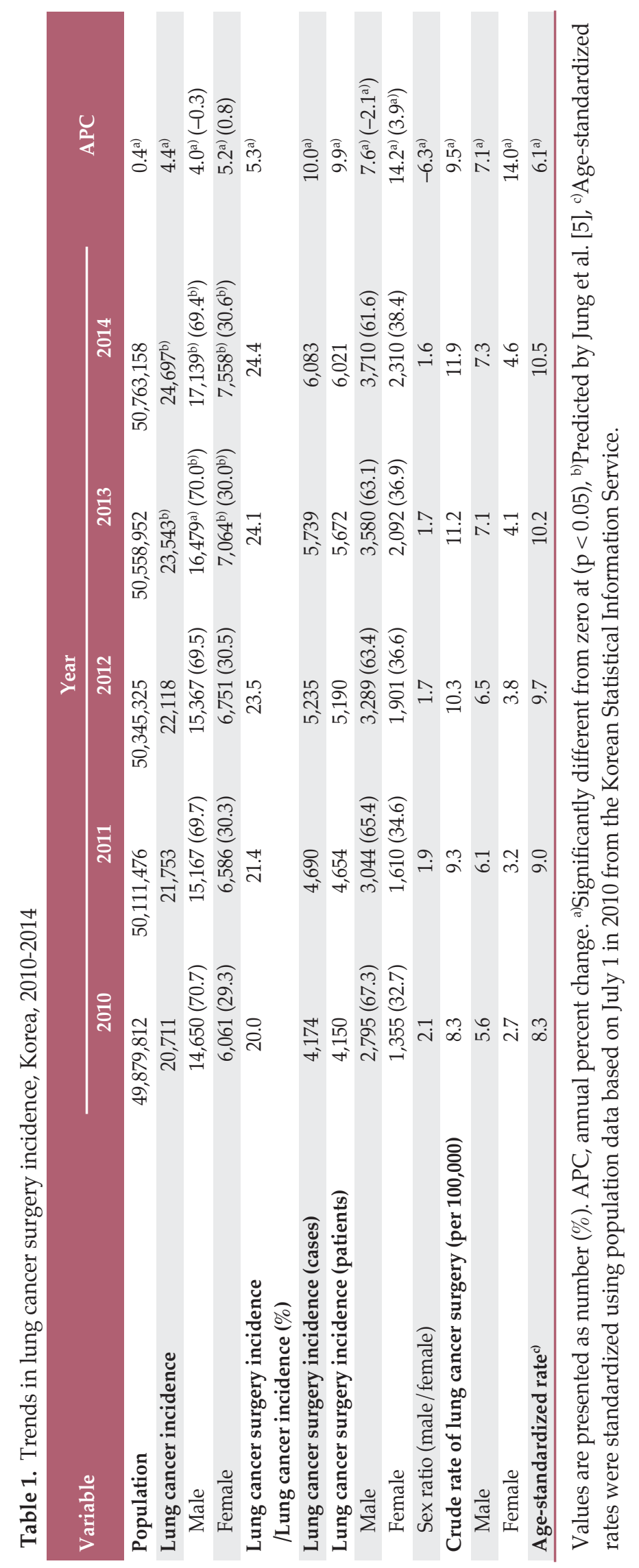




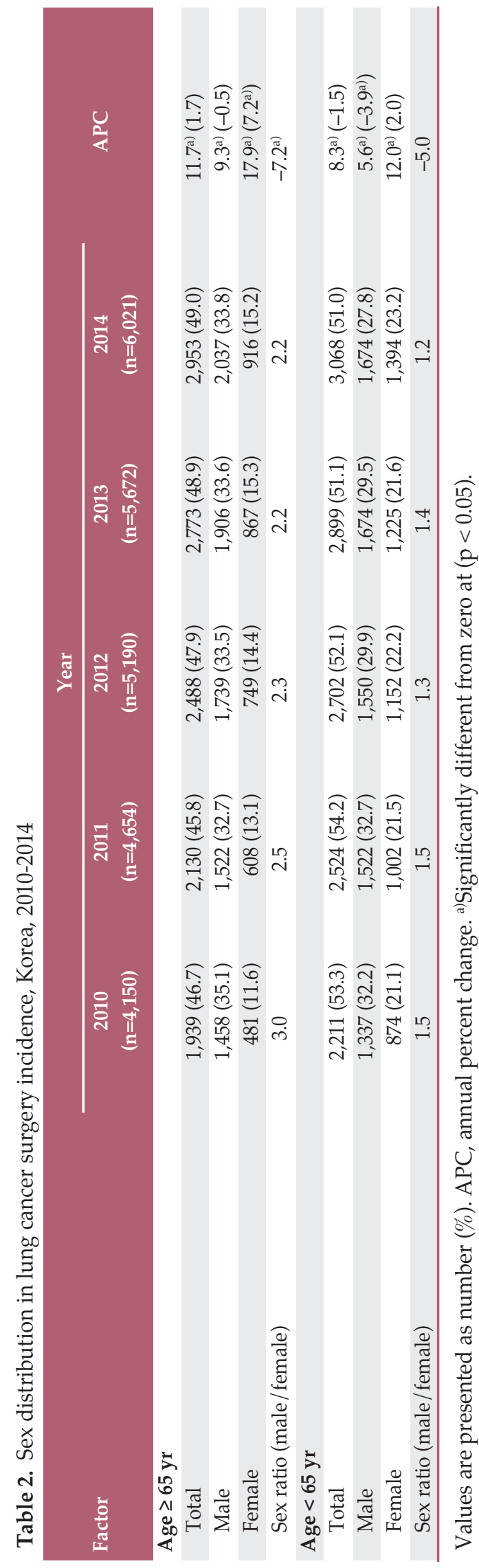

$\geq 70$ years accounted over $70 \%$ of cases among male patients, while the age groups of 50-59 years and 60-69 years accounted 60\% of female patients in 2014 .

\section{Incidence by resection type}

The incidences of segmentectomies (APC, 17.8; $\mathrm{p}<0.05$ ) and single lobectomies (APC, $7.5 ; \mathrm{p}<0.05)$ increased significantly over the study period, while the incidence of pneumonectomies decreased significantly (APC, $-6.3 ; \mathrm{p}<0.05$ ). The incidence of bilobectomies did not change significantly (APC, $-1.2 ; \mathrm{p}=0.7$ ). The proportions of segmentectomies (APC, 9.9; $\mathrm{p}=0.1$ ) and single lobectomies (APC, $0.4 ; \mathrm{p}=0.5$ ) increased, but this increase was not statistically significant. Otherwise, the proportions of extensive surgeries; namely, bilobectomies (APC, $-7.9 ; \mathrm{p}<0.05$ ) and pneumonectomies (APC, -12.5; $\mathrm{p}<0.05$ ), decreased significantly (Fig. 2).

\section{Incidence by regional distribution}

The incidence of surgeries performed in the Seoul Metropolitan area (the capital of Korea) and all other areas taken together increased significantly over the study period (Seoul: APC, 11.0; $<<0.05$; all others together: APC, 8.2; $<<0.05$ ). Approximately $60 \%$ of the total lung cancer surgeries over the study period were performed in Seoul. The proportion of patients operated on in Seoul increased significantly (APC, $1.1 ; \mathrm{p}<0.05)$, while the proportion in other areas significantly decreased (APC, $-1.5 ; \mathrm{p}<0.05$ ) (Fig. 3).

\section{Incidence by hospital size}

All lung cancer surgeries were performed in secondary or tertiary hospitals. However, the monthly incidence surgeries in tertiary hospitals increased consistently (APC, 12.5; $\mathrm{p}<0.05$ ), while the monthly incidence surgeries in secondary hospitals did not change significantly (APC, 3.9; $\mathrm{p}=0.2$ ) (Fig. 4).

\section{Discussion}

Lung cancer is the most common cancer and the leading cause of cancer death in the world [2]. In Korea, lung cancer is the third most common cancer in male patients and the fifth most common in female patients [4]. The age-standardized rate of lung cancer has not increased over the last five years; however, there has been a large change in the incidence pattern according to sex [1]. The incidence rate of lung cancer has declined in males and increased in females in 


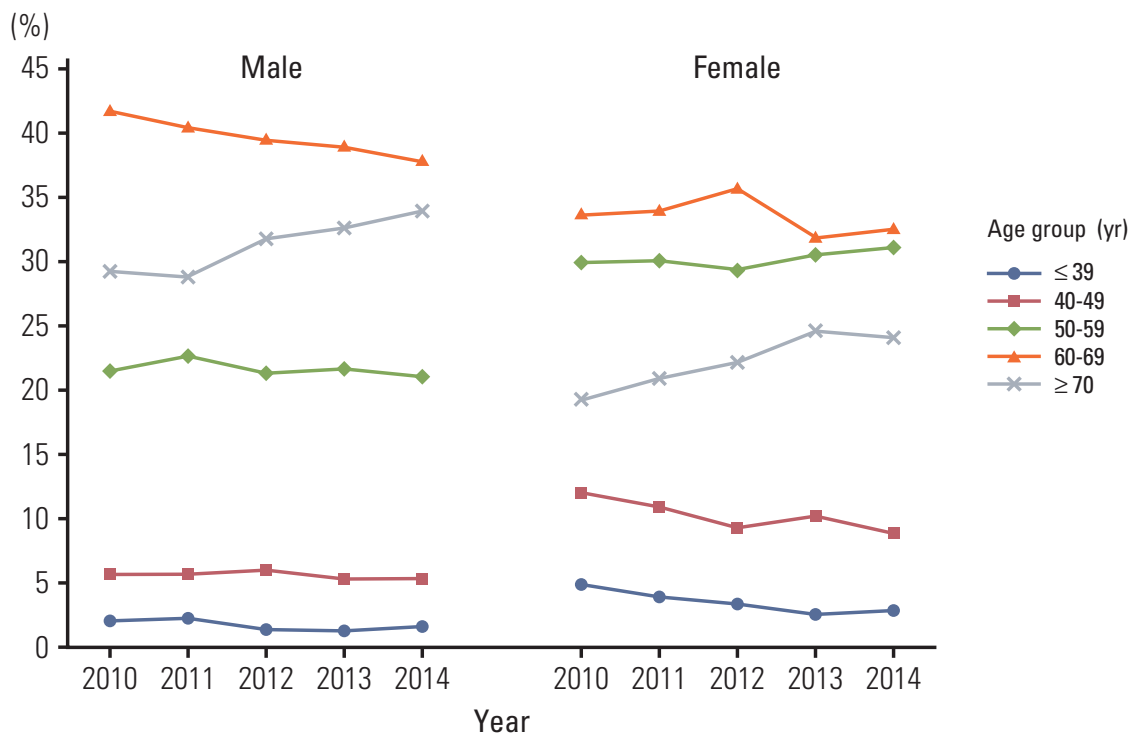

Fig. 1. Trends in age-specific incidence of lung cancer surgery by year.

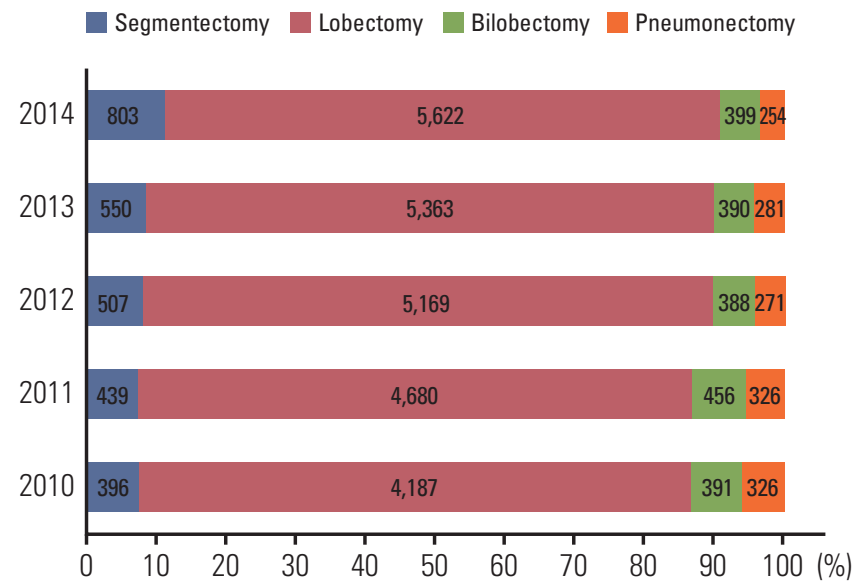

Fig. 2. Trends in type of surgery by year.

Korea, as well as in Japan and the United States [7,18]. Consequently, the number of lung cancer surgeries has increased and the composition of patients has changed in terms of sex ratio and age distribution [14,15,17]. In Korea, the incidence of lung cancer was 2.3 times higher in male patients than in female patients in 2012 [4]. However, the male-to-female ratio of lung cancer surgery was 1.6 in 2012. These findings suggest that lung cancer of an operable stage is more likely in female patients than in male patients, which may result from lung cancer screening in conjunction with the distinctive characteristic of lung cancer in non-smoking Asian

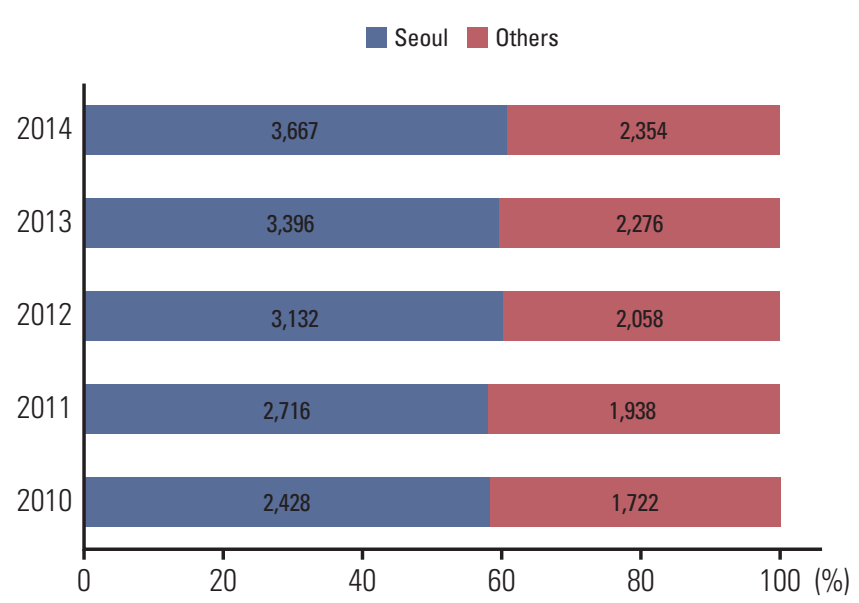

Fig. 3. Trends in area-specific incidence of lung cancer surgery by year.

females.

Lung cancer is a disease that commonly afflicts the elderly and is the most common cancer in male patients and the third most common in female patients aged $\geq 65$ years in Korea [1]. In 2012, patients aged $\geq 65$ years accounted for $75.4 \%$ of new lung cancer cases; however, only $47.9 \%$ of patients aged $\geq 65$ years underwent lung cancer surgery in Korea. Aging is a well-known definite risk factor for perioperative morbidities and mortality [19-21]. Some studies have raised concerns about the under-treatment of elderly patients $[22,23]$, and the incidence of lung cancer surgery in elderly 


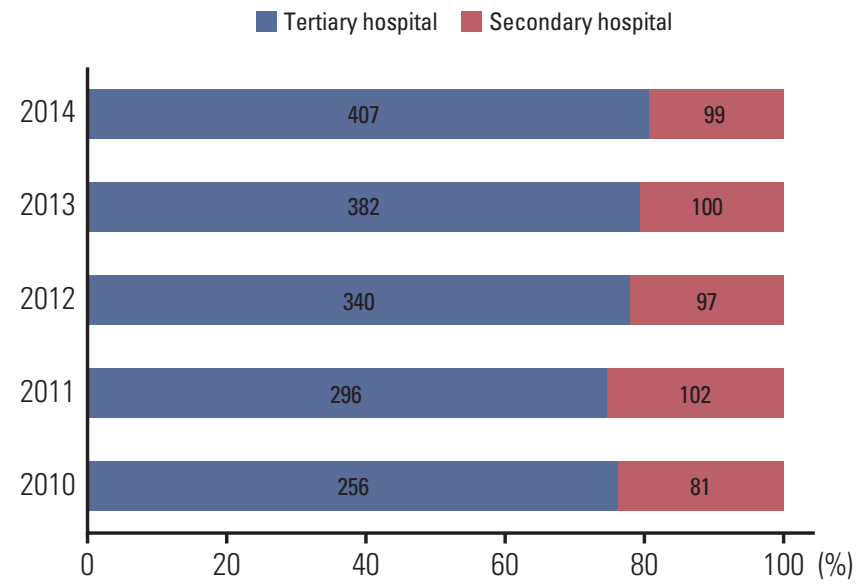

Fig. 4. Average monthly case of lung cancer surgery in tertiary hospitals by year.

patients has been increasing [16].

According to the United Nations, the number of persons aged $\geq 80$ years is expected to increase by a factor 10 from 2000 to 2050 in Korea [24]. Moreover, life expectancy is higher in females than in males $[4,12]$. Therefore, sophisticated surgical techniques and delicate perioperative management are essential to achieve successful surgical outcomes in elderly patients. Although elderly patients have commonly been considered to include patients aged $\geq 65$ years [19], an increase in the number of elderly patient can result not only from the population aging, but also from an increase in the number of physically competent elderly patients who can tolerate surgical management $[25,26]$. A Japanese study revealed that the physical activity of healthy elderly individuals was more youthful by 7.5 years among men and by 10 years among women in the 2002 cohort than in the 1992 cohort [25]. Consequently, the proportion of female elderly patients undergoing lung cancer surgery is expected to increase steadily in the future.

The surgical procedures for lung cancer have changed over the last few years. The use of pneumonectomy for lung cancer treatment has been declining worldwide [14-16]. Our study found a decrease in the use of pneumonectomy and bilobectomy for lung cancer treatment that could be associated with stage shifts following lung cancer screening with LDCT and changes in the dominant histology type of lung cancer [10,27]. A National Lung Cancer Screening Trial found that LDCT screening decreased the proportion of advanced lung cancer [10]. Additionally, the NELSON lung cancer screening study demonstrated that lung cancers detected upon screening were often diagnosed at stage I, and that the diagnosis was made at a more favorable stage in female than male patients [28]. In a LDCT screening study of
1,520 participants conducted by the Mayo Clinic, only two bilobectomies and no pnemonectomies were performed among 53 patients found to have lung cancer upon screening [29]. The International Early Lung Cancer Action Program study reported that $85 \%$ of diagnosed lung cancer cases (412/484) were clinical stage I, and that only 10 bilobectomies $(2.7 \%)$ and no pneumonectomies were performed among 375 lung cancer surgeries [30].

The centralization of lung cancer surgery is a somewhat distinctive phenomenon in Korea [17]. Although the nationwide incidence of lung cancer surgery has increased, this has only be experienced by tertiary hospitals. The case volumes in secondary hospitals have remained steady. Approximately $40 \%$ of tertiary hospitals designated by the Korean government (17/44) are located in the Seoul metropolitan area, which is home to $20 \%$ of the Korean population. However, over $60 \%$ of lung cancer surgeries were performed in tertiary hospitals in the Seoul metropolitan area over the last 5 years. Improvement in geographical accessibility and advanced transportation systems may have contributed to the centralization of lung cancer surgery in Korea. However, the primary reason is that people are opting for the most up-to-date and advanced treatments for lung cancer. Cancer management requires a multidisciplinary approach and involves surgical oncologists, pulmonologists, medical oncologists, radiologic oncologists, diagnostic radiologists, pathologists, and nursing staff as part of a well-organized team. Therefore, centralization to high-volume centers is an inevitable consequence, considering the social needs for efficient and qualified treatment. A positive relationship between hospital or surgeon volume and surgical outcomes has been established. However, efforts should be made to relieve centralization by maintaining the quality of lung cancer care in regional cancer centers to enable effective utilization of national health resources.

It should be noted that the present study has some limitations. Specifically, procedure code O1597 represents any mediastinal lymph node dissection with lung resection, regardless of the primary diagnosis. We could not identify lung cancer surgery without lymph node dissection or sampling. Although data based on the procedure code did not allow classification according to the primary diagnosis, anatomical pulmonary resection and mediastinal lymph node dissection/sampling are the standard surgical methods for primary lung cancer. Therefore, the proportion of cases not involving primary lung cancer and lung cancer surgery without lymph node evaluation was negligible in this investigation. Finally, data describing cancer stage and other co-morbidities were lacking, which influences the selection of the modalities for lung cancer treatment and surgical procedures. 


\section{Conclusion}

This is the first study evaluating changes in lung cancer surgery trend in Korea based on national healthcare data. Remarkable findings include an increase in the use of lung cancer surgery in elderly patients and female patients, and a decrease in the proportion of patients requiring extensive pulmonary resection. Centralization of lung cancer surgery was also noted. These changes are expected to continue and should be considered in the reforming of lung cancer management systems in Korea.

\section{Conflicts of Interest}

Conflict of interest relevant to this article was not reported.

\section{References}

1. Jung KW, Won YJ, Kong HJ, Oh CM, Cho H, Lee DH, et al. Cancer statistics in Korea: incidence, mortality, survival, and prevalence in 2012. Cancer Res Treat. 2015;47:127-41.

2. Ferlay J, Soerjomataram I, Dikshit R, Eser S, Mathers C, Rebelo $\mathrm{M}$, et al. Cancer incidence and mortality worldwide: sources, methods and major patterns in GLOBOCAN 2012. Int J Cancer. 2015;136:E359-86.

3. OECD.stat [Internet]. Paris: Organisation for Economic Co-operation and Development; 2015 [cited 2015 Dec 9]. Available from: http://stats.oecd.org/.

4. The Korea Central Cancer Registry, National Cancer Center. Annual report of cancer statistics in Korea in 2012 [Internet]. Goyang: National Cancer Information Center; 2014 [cited 2015 Oct 15]. Available from: http:// www.cancer.go.kr.

5. Jung KW, Won YJ, Oh CM, Kong HJ, Cho H, Lee DH, et al. Prediction of cancer incidence and mortality in Korea, 2015. Cancer Res Treat. 2015;47:142-8.

6. Dillman RO, McClure SE. Steadily improving survival in lung cancer. Clin Lung Cancer. 2014;15:331-7.

7. Siegel RL, Miller KD, Jemal A. Cancer statistics, 2015. CA Cancer J Clin. 2015;65:5-29.

8. The Korea Central Cancer Registry, National Cancer Center. Annual report of cancer statistics in Korea in 2011 [Internet]. Goyang: National Cancer Information Center; 2013 [cited 2015 Oct 15]. Available from: http:// www.cancer.go.kr.

9. The Korea Central Cancer Registry, National Cancer Center. Annual report of cancer statistics in Korea in 2010 [Internet]. Goyang: National Cancer Information Center; 2012 [cited 2015 Oct 15]. Available from: http:// www.cancer.go.kr.

10. National Lung Screening Trial Research Team, Aberle DR, Adams AM, Berg CD, Black WC, Clapp JD, et al. Reduced lung-cancer mortality with low-dose computed tomographic screening. N Engl J Med. 2011;365:395-409.

11. Korea Centers for Disease Control and Prevention. Korea Health Statistic 2013: Korea National Health and Nutrition Examination Survery (KNHANES VI-1) [Internet]. Cheongju: Centers for Disease Control and Prevention; 2013 [cited 2015
Oct 15]. Available from: http://knhanes.cdc.go.kr.

12. Population Division, Department of Economic and Social Affairs, United Nations. World population ageing 2013 [Internet]. New York: United Nations; 2013 [cited 2015 Dec 2]. Available from: http://www.un.org/.

13. Kwon S. Thirty years of national health insurance in South Korea: lessons for achieving universal health care coverage. Health Policy Plan. 2009;24:63-71.

14. Morgant MC, Pages PB, Orsini B, Falcoz PE, Thomas PA, Barthes FL, et al. Time trends in surgery for lung cancer in France from 2005 to 2012: a nationwide study. Eur Respir J. 2015;46:1131-9.

15. Strand TE, Bartnes K, Rostad H. National trends in lung cancer surgery. Eur J Cardiothorac Surg. 2012;42:355-8.

16. Riaz SP, Linklater KM, Page R, Peake MD, Moller H, Luchtenborg $\mathrm{M}$. Recent trends in resection rates among non-small cell lung cancer patients in England. Thorax. 2012;67:811-4.

17. Memtsoudis SG, Besculides MC, Zellos L, Patil N, Rogers SO. Trends in lung surgery: United States 1988 to 2002. Chest. 2006;130:1462-70.

18. Center for Cancer Control and Information Services, National Cancer Center. Cancer Statistics in Japan [Internet]. Tokyo: Center for Cancer Control and Information Services, National Cancer Center; 2014 [cited 2015 Dec 2]. Available from: http://ganjoho.jp/.

19. Kowdley GC, Merchant N, Richardson JP, Somerville J, Gorospe M, Cunningham SC. Cancer surgery in the elderly. ScientificWorldJournal. 2012;2012:303852.

20. Manceau G, Karoui M, Werner A, Mortensen NJ, Hannoun L. Comparative outcomes of rectal cancer surgery between elderly and non-elderly patients: a systematic review. Lancet Oncol. 2012;13:e525-36.

21. Milisavljevic D, Stankovic M, Zivic M, Stankovic P. Head and neck cancer surgery in elderly: complications and survival rate. Coll Antropol. 2012;36 Suppl 2:13-7.

22. McMahon M, Barbiere JM, Greenberg DC, Wright KA, Lyratzopoulos G. Population-based trends in use of surgery for 
non-small cell lung cancer in a UK region, 1995-2006. Thorax. 2011;66:453-5.

23. Peake MD, Thompson S, Lowe D, Pearson MG; Participating Centres. Ageism in the management of lung cancer. Age Ageing. 2003;32:171-7.

24. Population Division, Department of Economic and Social Affairs, United Nations. World population ageing 1950-2050 [Internet]. New York: United Nations; 2001 [cited 2015 Dec 2]. Available from: http://www.un.org/.

25. Orimo H, Ito H, Suzuki T, Araki A, Hosoi T, Sawabe M. Reviewing the definition of "elderly". Geriatr Gerontol Int. 2006;6:149-58.

26. Owonikoko TK, Ragin CC, Belani CP, Oton AB, Gooding WE, Taioli E, et al. Lung cancer in elderly patients: an analysis of the surveillance, epidemiology, and end results database. J Clin Oncol. 2007;25:5570-7.

27. Jie C, Wever AM, Huysmans HA, Franken HC, Wever-Hess J,
Hermans J. Time trends and survival in patients presented for surgery with non-small-cell lung cancer 1969-1985. Eur J Cardiothorac Surg. 1990;4:653-7.

28. Horeweg N, van der Aalst CM, Thunnissen E, Nackaerts K, Weenink C, Groen HJ, et al. Characteristics of lung cancers detected by computer tomography screening in the randomized NELSON trial. Am J Respir Crit Care Med. 2013;187: 848-54.

29. Crestanello JA, Allen MS, Jett JR, Cassivi SD, Nichols FC 3rd, Swensen SJ, et al. Thoracic surgical operations in patients enrolled in a computed tomographic screening trial. J Thorac Cardiovasc Surg. 2004;128:254-9.

30. International Early Lung Cancer Action Program Investigators, Henschke CI, Yankelevitz DF, Libby DM, Pasmantier MW, Smith JP, et al. Survival of patients with stage I lung cancer detected on CT screening. N Engl J Med. 2006;355: 1763-71. 